\title{
Imagens e narrativas da Coimbra turística: Entre a cidade real e a cidade (re)imaginada
}

Images and Narratives of Coimbra as a Tourist Destination: Between the Real Town and the (Re)imagined Town

Images et narrations de Coimbra touristique: Entre la ville réelle et la ville (ré)imaginée

\section{Carina Sousa Gomes}

\section{OpenEdition}

\section{Journals}

Edição electrónica

URL: http://journals.openedition.org/rccs/448

DOI: $10.4000 /$ rccs. 448

ISSN: 2182-7435

\section{Editora}

Centro de Estudos Sociais da Universidade de Coimbra

\section{Edição impressa}

Data de publição: 1 Dezembro 2008

Paginação: 55-78

ISSN: 0254-1106

\section{Refêrencia eletrónica}

Carina Sousa Gomes, «Imagens e narrativas da Coimbra turística: Entre a cidade real e a cidade (re)imaginada ", Revista Crítica de Ciências Sociais [Online], 83 | 2008, colocado online no dia 01 dezembro 2012, criado a 01 maio 2019. URL : http://journals.openedition.org/rccs/448 ; DOI $10.4000 /$ rccs. 448

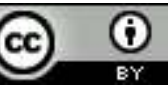




\title{
CARINA SOUSA GOMES
}

\section{Imagens e narrativas da Coimbra turística: Entre a cidade real e a cidade (re)imaginada'}

\begin{abstract}
Num período em que se verifica um crescimento do fascínio turístico pelas cidades, este artigo procura compreender as formas como Coimbra se apresenta ao exterior, a turistas e visitantes. Sendo a cidade histórica e monumental uma das principais atracções da actualidade, parte-se dos materiais de promoção turística, que circulam nacional e internacionalmente, para abordar as formas como os recursos urbanos são transformados em factores de atracção turística.

Porque as cidades são também lugares de imaginação e representação, discute-se a noção de imagem por referência às operações de marketing e publicidade que se desenvolvem no quadro da promoção turística. O objectivo fundamental é desvendar a cidade (re)imaginada: aquela que, através do trabalho de tradução simbólica desempenhado por agentes promocionais e mediadores, circula pelos mercados do turismo - desvendando também as aproximações e distâncias entre a cidade turística e a cidade real.
\end{abstract}

Palavras-chave: turismo urbano, promoção turística, imaginários urbanos, narrativas turísticas.

\section{Introdução}

Nas sociedades modernas ocidentais, os fenómenos do lazer e do turismo vêm-se revelando factores decisivos de reorganização dos territórios, das condições de ordenamento do espaço e das políticas de planeamento e desenvolvimento, com uma especial visibilidade nos espaços urbanos. Paralelamente, envolvem complexos processos de recriação de imagens e narrativas sobre as cidades. Articulados com transformações morfológicas e funcionais do espaço urbano, esses processos não são relevantes apenas para

\footnotetext{
${ }^{1}$ Este artigo resulta de investigação desenvolvida no âmbito do projecto "Fluxos turísticos no centro histórico de Coimbra - gestão integrada de equipamentos turísticos urbanos", realizado no âmbito do Centro de Estudos Sociais e apoiado pela Direcção Geral de Turismo e o Instituto de Turismo de Portugal, através do programa PIQTUR (projecto 214/DGT/2005). A investigação serviu também de base à elaboração de uma dissertação de mestrado, cujos resultados se retomam parcialmente aqui (Gomes, 2008). Um agradecimento especial a Claudino Ferreira e Paula Abreu pelas leituras cuidadas e enriquecedoras do artigo.
} 
o modo como turistas e visitantes se relacionam com a cidade. São-no também para o modo como, de forma mais ampla, se redefine continuamente a identidade dos lugares, se estabelecem agendas políticas para o planeamento do espaço urbano e se refazem as formas de relacionamento com a cidade.

Seguindo esta linha de problematização, este texto apresenta uma abordagem sociológica da dimensão turística de Coimbra e do modo como a cidade é turisticamente imaginada e narrada. Atentando nas dimensões simbólicas do fenómeno, a análise centra-se sobre as imagens e narrativas da cidade que são (re)criadas e mobilizadas nos mercados do turismo. A questão que aqui se levanta é a de saber quais os elementos e recursos que são valorizados ou menosprezados, mobilizados ou esquecidos, na promoção turística da cidade. A dualidade é importante, na medida em que essa promoção está estreitamente ligada a processos de selecção e visibilidade de certas características do local e de esquecimento ou desprezo de outras; de criação de sistemas de imagens, coerentes ou não com a história do lugar, que possam ser usadas para a construção de um imaginário turístico atractivo.

Para além de tudo o resto, as cidades são também conjuntos de símbolos que, ao longo da história, vão sendo hierarquizados e expressos, tanto nas estruturas físicas, como nos aspectos da vida quotidiana e nos discursos sobre elas (Shields, 1992: 29). Neste sentido, ao falar de cidades, falamos igualmente das imagens que lhes vão sendo associadas, assim como dos interesses e dos poderes que estão na sua origem (Baptista, 2003: 35-40).

Sendo frequentemente reconhecida como "uma das mais míticas e lendárias cidades portuguesas” (Fortuna e Peixoto, 2002: 28), Coimbra é recorrentemente caracterizada nos mercados turísticos como cidade histórica, patrimonial e monumental, académica e universitária. Variável é o cariz mais ou menos vincado com que cada um destes argumentos é mobilizado, posicionando a cidade de formas distintas nos mercados nacionais e internacionais, conforme os actores que lhes dão forma e visibilidade, os objectivos de cada um e, necessariamente, os públicos a que se dirigem. São precisamente estas variações que tornam esta cidade um objecto particularmente interessante de pesquisa, sobretudo pelos modos como os seus diferentes recursos são usados para a (re)criação de imagens atractivas para o lugar.

\section{Cidades históricas, turismo urbano e patrimonial}

No quadro da diversificação e da segmentação da oferta e da procura turísticas, ocorridas ao longo da segunda metade do século XX, um tipo singular de turismo foi ganhando um fulgor renovado: aquele "que se desenrola 
em contextos urbanos, particularmente os que registam uma forte incidência de factores arquitectónicos, histórico-arqueológicos e monumentais" (Fortuna, 1999: 48). Se é verdade que as cidades, enquanto centros de arte, cultura e património, sempre constituíram lugares de relevo dos circuitos turísticos, o turismo urbano e cultural vem vivendo, ao longo das últimas décadas, um impulso assinalável, no âmbito do qual adquire novos contornos. E embora, como refere C. Fortuna (ibid.), este tipo de turismo não escape às orientações mais gerais de organização e mercantilização subjacentes ao desenvolvimento do turismo de massas, não deixa também de registar especificidades que importa assinalar.

São de sublinhar, a este respeito, algumas tendências que impulsionaram e acompanharam a eclosão do turismo urbano na Europa (cf. Gómez, 1998). Em primeiro lugar, desenvolveu-se a mobilidade recreativa e, particularmente, o turismo de curta duração. Segundo, verificou-se uma renovada atracção pelos recursos e produtos culturais e patrimoniais que as cidades concentram: eventos e exposições, grandes infraestruturas e equipamentos culturais, espaços dotados de elevado valor patrimonial e simbólico, como os centros históricos, que foram incorporando, crescentemente, actividades de recreação e animação. Por fim, avançou uma nova geração de políticas de regeneração das paisagens urbanas, baseada no princípio de que a captação dos mercados e dos fluxos turísticos constituiria um importante factor de competitividade das cidades no sistema urbano globalizado.

Tudo nas cidades se tornou, por esta via, negociável e mercadorizável. Como refere C. Fortuna, sobre as cidades de Évora e Coimbra, "a 'indústria' do turismo objectifica e mercadoriza as cidades e os monumentos, a natureza e as paisagens, os costumes e os sentimentos" (Fortuna, 1999: 57).

O fascínio turístico pelas cidades está relacionado, hoje mais do que nunca, com a sua temporalidade e, por isso, a cidade histórica e monumental tornou-se uma das principais atracções da actualidade (Fortuna e Ferreira, 1996: 8). Tanto pela importância da cultura visual, como pela relevância do factor histórico das cidades, a sua arquitectura histórico-monumental converteu-se no elemento por excelência da identidade local, e também no recurso que mais interesse e curiosidade suscita entre os turistas. Trata-se de "patrimónios históricos edificados, mas também patrimónios socioculturais, artísticos, linguísticos e humanos que encontram expressões diversas nas cidades de hoje" (Fortuna, 2006: 3). Por outras palavras, como factor de atracção turística, o património está tão ligado aos aspectos físicos, enquanto património material e edificado, como aos aspectos socioculturais dos contextos urbanos, enquanto património imaterial, cultural e simbólico. Neste processo, a equação cidade, cultura e património foi-se configurando 
como um segmento turístico em plena expansão e com um enorme poder de sedução, tanto para consumidores e viajantes, como para os poderes públicos e os investidores no território urbano.

$\mathrm{Na}$ relação turística com as cidades, as noções de cultura, de história e de património tendem a confundir-se através da sujeição de todos os recursos possíveis - nomeadamente arte, património, história, modos de vida a uma apropriação eminentemente cultural. Tudo é passível de ser apropriado na cidade, numa relação de sentido, com uma forte componente estética e simbólica, tanto da parte dos promotores e agentes turísticos, como da parte dos turistas e visitantes. Os desenvolvimentos mais recentes na indústria turística dão-se precisamente nesse sentido: a valorização crescente das atracções culturais e lúdicas, e o alargamento do universo da cultura para a incorporação de um número crescente de elementos numa experiência que se pretende cultural.

Em resultado, no quadro da experiência turística, a concepção de cultura e do que tem valor cultural estende-se e flexibiliza-se, promovendo as mais diversas formas de diálogo entre arte, património, modos e estilos de vida das populações locais. Essa flexibilização vai no sentido dos processos teorizados por A. F. da Costa (1999: 171-188), quando propõe a noção de modos de cultura que, não distinguindo entre o que é mais ou menos cultural, dá o devido destaque às lógicas simbólicas e sociais que constituem cada um desses modos de cultura, superando entendimentos essencialistas ou elitistas de cultura.

O facto de nos encontrarmos numa fase de proliferação de atracções turísticas implica, por parte dos mercados, uma busca crescente do que é original e autêntico numa região, ainda que, como afirma D. MacCannel (1999), a realidade que é dada a conhecer ao turista não seja mais do que uma encenação, uma realidade manipulada ou fabricada pela indústria turística. Uma autenticidade encenada para a qual o próprio turismo contribui porque, ao promover objectos com valores culturais distintos, atribui-lhes sentidos diferentes daqueles que possuíam originalmente ou diferentes dos que lhes são atribuídos pelas populações locais. É através de processos deste tipo que algumas experiências são inventadas, em locais onde nunca existiram, em que festivais, cerimónias religiosas ou danças perdem o seu significado original ou sequência anual (Orbasli, 2000).

Alguns lugares tornam-se atracções turísticas obrigatórias devido a essa procura de significados originais por parte dos turistas. Ainda assim, a busca da autenticidade é apenas uma das fórmulas que alimentam o turismo urbano e cultural, apresentando-se com uma importância acrescida no caso em estudo sobre Coimbra. Outras fórmulas podem, no entanto, ser enunciadas, 
nomeadamente, da oferta artística e de elementos raros em domínios tão diversos quanto os do lazer, da arquitectura, do urbanismo ou das subculturas urbanas universitárias e alternativas. Tanto as motivações turísticas, como os imaginários e as experiências criadas pela oferta dos promotores turísticos para a cidade de Coimbra, constituem uma entre várias equações possíveis que, no seu conjunto, configuram o turismo urbano como um mercado muito heterogéneo.

\section{Representações, imagens e narrativas sobre as cidades}

As cidades não são apenas espaços materiais ou vividos; são igualmente espaços de imaginação e de representação. Isto acontece porque vários planeadores urbanos idealizam o aspecto físico das cidades, o seu funcionamento e as formas de serem vividas e esses ideais traduzem-se, por sua vez, em planos e ambientes construídos. Simultaneamente, as cidades são representadas em diversas formas artísticas (literatura, cinema, música, pintura e fotografia) e estas representações produzem também os seus efeitos sobre os lugares. A memória colectiva e o imaginário público sobre as cidades são, eles próprios, construídos e transformados por narrativas, imagens e representações que organizam a dimensão simbólica do espaço urbano (Boyer, 1998; Bridge e Watson, 2003: 7).

Pelo menos desde o século XVIII em diante, os romances ajudaram a criar a cidade como uma categoria empírica para o público leitor, disseminando determinadas formas de ver a paisagem urbana e de perspectivar a vida dos cidadãos. No decorrer do século XX, no entanto, as narrativas e as imagens associadas às cidades ao longo dos séculos anteriores foram-se distanciando das novas realidades urbanas; foram ultrapassadas pelos ritmos e rotinas impostos pelos novos meios de transporte, as novas formas de comunicação e os novos processos de reabilitação dos centros antigos das grandes cidades (Donald, 2003: 48-49). Deste ponto de vista, as novas realidades urbanas concorreram, também elas, para transformar as imagens, as narrativas e as representações sobre as cidades.

O trabalho de R. Chartier (1988: 17), a propósito do objecto da história cultural, encara as representações do mundo social como esquemas de "classificações, divisões e delimitações que organizam a apreensão do mundo social como categorias fundamentais de percepção e de apreciação do real". Estes esquemas variam de acordo com as classes sociais e os meios intelectuais onde são produzidos, não sendo universais mas determinados "pelos interesses de grupo que os forjam". Aplicada ao contexto urbano, a proposta de Chartier implica, necessariamente, pensar as representações sobre as cidades como plurais ou até opostas. Se essas representações dependem dos 
interesses específicos de determinados grupos, não surpreenderá que exista, em graus variáveis, alguma competição e conflitualidade entre elas. Chartier chama precisamente a atenção para essa possibilidade conflitual, equiparando a importância das lutas de representações às lutas económicas na imposição de valores e de visões do mundo social por parte de um grupo.

Apresentando-se como sistemas sociais complexos, as cidades propiciam o desenvolvimento de visões plurais, distintas e, por vezes, rivais, não podendo, por isso, ser representadas numa só imagem ou reduzidas a uma única narrativa.

No livro A Imagem da Cidade, ainda que dedique a sua atenção aos elementos físicos da imagem das cidades, K. Lynch (1988: 57) reconhece a existência de um outro conjunto de factores influenciadores dessa imagem: "o significado social de uma área, a sua função, a sua história, ou até, o seu nome". As vias, limites, bairros, cruzamentos e elementos marcantes seriam, em contraste, as formas físicas estruturantes das imagens individuais sobre as cidades. Esses elementos possuem imaginabilidade - a qualidade que lhes permite provocar a evocação de uma imagem mental a um dado indivíduo (ibid.: 20). Neste sentido, Lynch refere-se a imagens como representações mentais que podem ser influenciadas por factores imateriais, mas que são estruturadas principalmente por referência a elementos materiais das cidades. Ainda que possam ser mais ou menos partilhadas, essas imagens não deixam de ser representações mentais individuais.

A formação de uma imagem, como representação individual sobre uma cidade, pode ocorrer de diversas formas: através da influência de livros, filmes, postais, músicas, conversas, páginas electrónicas, para além da efectiva visita ao lugar, que não tem necessariamente que ocorrer. Mas essa imagem individual é também construída por referência aos elementos da cidade que são publicitados por actores específicos, directa ou indirectamente ligados à promoção turística. Deste ponto de vista, as imagens como representações mentais são influenciadas tanto pela experiência individual, como pelas imagens publicitárias que o marketing territorial promove. Neste último sentido, passa-se do domínio das imagens como construção individual para o domínio da produção imagética mais vasta, das imagens na sua forma descritiva, como frases ou expressões produzidas explicitamente para apresentarem alguma coisa num sentido atractivo, com o objectivo de influenciar a opinião pública, criando uma concepção generalizada sobre a cidade.

Estes diversos domínios em que a noção de imagem é usada, bem como a crescente diversificação de sentidos que lhe são atribuídos no discurso sociológico, acusam não só a relativa ambiguidade da própria noção, como 
as dificuldades de delimitação em relação a outras noções (estereótipo, narrativa e representação social) e entre linguagens disciplinares diferentes.

A ambivalência está também presente na literatura da gestão e do marketing turístico. Nomeadamente a nível nacional, discute-se a questão da atractividade das marcas e do ciclo de vida dos destinos, definem-se os elementos que contribuem para aumentar a atractividade da cidade enquanto produto turístico e elaboram-se sistemas de avaliação da imagem dos destinos. No entanto, pouco se escreve sobre a definição do conceito de imagem e mais raramente ainda ele é problematizado.

P. Kotler, um dos autores mais citados a nível nacional, defende que a imagem de um lugar corresponde à soma das convicções, crenças, ideias e impressões que as pessoas desenvolvem em relação a esse lugar (Kotler et al., 1993; Kotler e Haider, 1994). Esta definição, no entanto, é de tal forma ampla que se aproxima da noção de cultura, nomeadamente no sentido antropológico de C. Geertz (1973: 214-222). ${ }^{2}$ Do ponto de vista sociológico, ela não parece, portanto, operacionalizável: porque tudo é visto como imagem de um lugar; e porque os elementos a que Kotler se refere são parte integrante da experiência individual, não remetendo directamente para o domínio das imagens produzidas no âmbito publicitário.

Numa tentativa de sistematização, entendo as imagens das cidades como as expressões que as descrevem de modo lírico e que, do ponto de vista da sua produção no quadro do turismo, são promovidas em variados circuitos de difusão, através de acções de publicidade e marketing, e pela mediação de actores específicos. São, portanto, imagens publicitárias que têm como objectivo influenciar a opinião individual. Nessa medida, entendo-as, também, do ponto de vista da construção individual, como representações mentais, ancoradas em elementos físicos ou imateriais das cidades, influenciadas tanto pela experiência individual como por esse trabalho publicitário mais vasto. Neste último sentido, traduzem-se em representações restritas e sintéticas sobre os lugares, aproximando-se dos estereótipos, enquanto representações sociais simplistas, recorrentes, e mais ou menos institucionalizadas.

C. Fortuna e P. Peixoto (2002: 17) defendem que as imagens possíveis de um objecto correspondem ao "vasto leque de visões que um objecto pode suscitar a partir das suas múltiplas características”. Falando de cidades,

\footnotetext{
${ }^{2}$ C. Geertz define a cultura como teias de significação que os próprios indivíduos tecem, como o contexto através do qual os factos sociais, os comportamentos, as instituições ou os processos se tornam inteligíveis. Ora, esse contexto tem que estar necessariamente relacionado com um conjunto de convicções, crenças, ideias e impressões que permitem ao indivíduo dar sentido à realidade social que o rodeia.
} 
esta expressão significa que, do ponto de vista da produção imagética, é possível apresentar as cidades a partir de mais do que uma imagem publicitária, e que, do ângulo da recepção individual, uma cidade pode provocar a evocação de várias representações mentais.

No seio das operações de marketing e publicidade que se desenvolvem no quadro da promoção turística e, em particular, no seio da análise sociológica sobre essas operações, outra noção surge recorrentemente - a de narrativa. No Dicionário Houaiss da Língua Portuguesa (2003: 2588), narrativa é definida como conto ou história, como a exposição de um acontecimento ou de uma série de acontecimentos mais ou menos encadeados, reais ou imaginários, por meio de palavras ou de imagens. Desta ideia mais restrita, de narrativa como forma de contar uma história ou uma experiência, o conceito foi progressivamente ampliado, passando a ser usado em contextos variados para referir interpretações e relatos de diversos níveis. A noção passou a estar muito para além dos trabalhos artísticos tradicionalmente estudados no contexto da literatura (Finnegan, 1998: 4-9). No quadro do turismo, convém entender as narrativas, "na condição de metáforas tomadas por empréstimo do mundo literário" (Barreira, 2005: 300), como expressões de discursos instituídos, originários de fontes diversas. Discursos "não apenas fruto de práticas e intervenções de diferentes a[c]tores sociais, mas expressão de formas legitimadas de apresentar a cidade" (ibid.). $\mathrm{Na}$ experiência turística, o narrador é substituído por roteiros ou guias turísticos, que utilizam uma linguagem atractiva, apelando a sentimentos positivos por parte do turista.

Atente-se numa conhecida expressão portuguesa: "Lisboa diverte-se, o Porto trabalha, Coimbra estuda, Braga reza”. Sendo uma expressão simplista "de uma realidade mais complexa, este tipo de expressões mnemónicas resumem a identidade das cidades a um estereótipo produzido a partir da selecção de características marcantes e evidentes dos lugares em causa" (Fortuna e Peixoto, 2002: 17). De acordo com esta visão estereotipada, Lisboa ostenta a imagem de uma cidade diversora, o Porto a imagem de uma cidade trabalhadora, Coimbra é a cidade dos estudantes e Braga a cidade religiosa. A estas quatro cidades, poderia juntar-se Guimarães como cidade berço, Aveiro como a Veneza portuguesa ou Évora como cidade museu. A partir destas imagens sintéticas das quatro cidades, destes estereótipos, constroem-se narrativas urbanas mais amplas, ancoradas na história particular de cada cidade, ou (re)inventadas a partir da intervenção de actores ou processos específicos. Essas narrativas vão sendo incorporadas tanto pelas populações locais, como pelos poderes públicos, como por turistas e visitantes. 
O turismo e as actividades que daí decorrem são, aliás, um dos meios hoje mais poderosos de criação e difusão destas imagens e narrativas urbanas. A busca de uma imagem distintiva e a procura de qualidades especiais são tarefas a que muitos actores, grupos ou instituições se entregam, em nome das cidades, para a construção de narrativas e de imaginários urbanos e, pela sua tradução em obra física, em paisagens construídas, que atraiam e satisfaçam a procura turística. Os postais, os roteiros para visitantes e os guias turísticos, por exemplo, são elaborados de forma a mostrarem certas fotografias da cidade e não outras, a contarem partes seleccionadas da história do lugar, a revelarem determinadas palavras e não outras, a sugerirem algumas experiências urbanas possíveis entre muitas outras. Na sua análise do Guia Azul, R. Barthes (1957: 115) alertava já para o cariz selectivo dos guias. O mesmo pode dizer-se dos outros tipos de materiais de promoção turística: eles são uma forma de apresentar a cidade segundo as narrativas desse lugar; não dizem propriamente o que a cidade é, antes apresentam uma cidade, ou várias cidades, idealizada(s), a partir das suas imagens mais atractivas.

\section{Coimbra, e a cidade idealizada nos guias de viagem}

A cidade real, a mais importante da Região Centro, capital de distrito e sede de município, com a sua longa história, ${ }^{3}$ as suas dinâmicas de expansão geográfica, a sua população e as actividades que lhe dão vida, coexiste com a cidade dos imaginários, das representações e das percepções que se produzem e se difundem nesses outros circuitos que, como refere J. Urry (1990), (re)criam as imagens turísticas do lugar e concorrem para construir socialmente a experiência que nele procuram os turistas: os circuitos alimentados pelos relatos ou literatura de viagem, os registos mais etnográficos, os guias e materiais de promoção turística do lugar.

Para aceder a esse imaginário sobre a Coimbra turística, recorro, de momento, a três fontes que constituem espaços interessantes de (re)construção de narrativas urbanas: o Guia Expresso das Cidades e Vilas Históricas de Portugal (1996), ${ }^{4}$ o Guia de Portugal (1988 [1924] $)^{5}$ e o Guia American Express: Portugal (2007), ${ }^{6}$ seleccionados por possibilitarem uma análise

\footnotetext{
3 Veja-se, a respeito da contextualização histórica e demográfica da cidade de Coimbra: Gomes (2007 e 2005), M. Gomes (1995), Rosmaninho (2006) e Rossa (2006).

${ }^{4}$ Refiro-me ao Vol. 7 da colecção, dedicado a Coimbra, Montemor-o-Velho e Figueira da Foz.

5 Refiro-me ao $3^{\circ}$ Vol., dedicado à Beira Litoral. Os volumes foram publicados entre 1983 e 1988 pela Fundação Calouste Gulbenkian, mas reproduzem fielmente a primeira edição de 1924, da Biblioteca Nacional de Lisboa.

6 Guia dividido por áreas, que não correspondem a divisões administrativas. Coimbra insere-se, aqui, nas Beiras. Conta com vários colaboradores, mas o seu organizador é Ferdie McDonald, responsável pelo projecto.
} 
longitudinal em perspectiva comparada. O objectivo desta primeira aproximação aos imaginários turísticos passa por desvendar se os recursos promovidos a nível nacional, no Guia Expresso, são semelhantes aos que se promovem fora do país, analisando-se, para isso, o Guia American Express, internacionalmente difundido. Por outro lado, através do Guia de Portugal da Fundação Calouste Gulbenkian, pretende-se perceber se se trata de elementos recentes na promoção da cidade ou se, pelo contrário, a cidade continua a fazer-se valer de recursos já importantes no passado.

No primeiro, ${ }^{7}$ J. H. Saraiva começa por descrever historicamente a cidade, destacando-lhe o papel importante como primeira capital do reino, mas também o estatuto do Paço de Coimbra, que D. João III terá oferecido para a sede da universidade. Com esta cedência, ter-se-á formado a complementaridade entre as ideias de Universidade e de Coimbra, pelo que esta terá passado "a ser a cidade dos estudantes". Na segunda rubrica sobre a cidade, W. Rossa defende que, para entender a sua posição na história, é fundamental "esse fatalismo geográfico que lhe determinou papéis vários de centralidade, fronteira, portagem, encruzilhada a diversas escalas ao longo do tempo" (Rossa, 1996: 5). Na última rubrica, os autores elaboram um retrato demográfico, reflectindo os elevados índices de envelhecimento, e dedicam-se a uma caracterização das actividades económicas, concluindo que Coimbra surge como uma cidade essencialmente prestadora de serviços.

Depois destas descrições, um mapa revela quarenta pontos considerados notáveis, de cariz monumental e, a seguir, três percursos possíveis para conhecer a cidade: "Coimbra dos Amores", "Coimbra dos Futricas" e "Coimbra dos Doutores". Trata-se de um guia com aspectos muito técnicos, dados estatísticos, taxas e índices de desenvolvimento. Paralelamente, utiliza um estilo de linguagem directo, objectivo e dotado, até, de alguns laivos de crítica, em contraste, nomeadamente, com o Guia de Portugal, de Sant'Anna Dionísio. ${ }^{8}$

Neste último nota-se uma demora incomparavelmente maior em cada assunto tratado, visível, nomeadamente, na proposta de permanência de três dias em Coimbra, necessária para conhecer a cidade. Com um cariz bastante mais histórico e muito mais próximo da literatura de viagens, este guia tem início com uma série de indicações sobre infraestruturas, modos de deslocação, comércio e indústrias, hotelaria e restauração, festas, feiras

\footnotetext{
${ }^{7}$ Este volume conta com a colaboração do historiador José Hermano Saraiva, do arquitecto Walter Rossa e dos geógrafos Luciano Lourenço e Mário Matos.

8 Sant'Anna Dionísio assumiu a responsabilidade de conclusão da obra, pela morte de Raul Proença. Contribuíram também para este volume Afonso Lopes Vieira, António Sérgio, Aquilino Ribeiro, Câmara Reys, Ferreira de Castro, Raul Lino, Reynaldo dos Santos e Samuel Maia.
} 
e romarias na cidade. Passa-se, depois, para uma descrição da fisionomia da cidade, em que lhe são atribuídos os títulos de "cidade fundamentalmente escolar, dotada de uma das universidades mais antigas da Europa, [...] a quarta cidade portuguesa, sede de distrito, de bispado e duma região militar, capital da província da Beira Litoral” (Dionísio, 1988: 179). Em toda esta parte se faz um elogio à cidade, notório na linguagem utilizada, que apela aos sentimentos, à emoção e ao afecto por Coimbra, cujo aparecimento "é uma maravilhosa surpresa”.

Depois destas notas emocionadas, faz-se uma descrição pormenorizada da história da cidade. Através das referências temporais da descrição, vão sendo destacados alguns pontos interessantes, como sejam o seu papel importante na formação da nacionalidade, o seu estatuto como "centro de cultura do País" e a sua transformação, durante os tempos modernos, numa "cidade universitária", devendo "à sua vida académica e ao ambiente de poesia e lenda o renome e o carácter", mas também o título de "mais romântica de todas as cidades portuguesas", de "mais formosa e típica entre os formosos burgos da Península" e de "centro de actividade literária" (ibid.: 186-187). A relação estreita entre a cidade, a universidade e a vida académica, cultural e artística é uma constante.

A descrição mais minuciosa da cidade é feita com base na sugestão de um itinerário, pela Baixa e pela Alta, para o qual são necessários pelo menos três dias. No percurso pela Baixa, dá-se mais atenção ao comércio, nomeadamente "à Rua do Visconde da Luz que, com a Rua de Ferreira Borges, constitui a artéria comercial mais importante da cidade" (ibid.: 209). Já na Alta, dá-se ênfase à Universidade, aos estudantes, às repúblicas e ao fado. O itinerário para conhecer Coimbra termina na "parte moderna da Cidade", pois esta tem vida própria e já não depende exclusivamente dos estudantes universitários.

Contrastando com o Guia de Portugal, longo, minucioso, demorado no elogio de cada detalhe, o Guia American Express: Portugal é muito mais sucinto, directo na transmissão das informações, breve nas descrições, bem ao estilo do novo turista apressado que, em vez de três dias na cidade, se permite despender apenas uma manhã ou uma tarde. Neste guia, Coimbra é "a velha cidade universitária" que merece ser explorada e constitui um bom ponto de ligação para outros locais nas Beiras. O que aqui se destaca é o berço de seis reis de Portugal, o título de capital até 1256 e a sede da mais antiga universidade do país. Coimbra representa, para os portugueses "as raízes da nação. Para os visitantes é um tesouro de fascinantes associações históricas” (McDonald, 2007: 202).

A descrição da cidade faz-se com base na conhecida dualidade do espaço urbano, mas com outro elemento: o outro lado do Rio Mondego. Na Baixa, 
dá-se destaque às lojas, bares, restaurantes e pastelarias, mas também a um grande número de igrejas. Já na Alta faz-se referência à entrada para a cidade velha, às repúblicas e às duas catedrais da cidade que se erguem na sombra da Universidade. Por fim, do outro lado do Mondego, merecem destaque os aspectos lendários: Santa Isabel, Inês de Castro e a Fonte dos Amores, que pode ser vista na Quinta das Lágrimas.

À parte desta exposição faz-se o desafio "À Descoberta de Coimbra”, rubrica que começa por chamar a atenção para o afecto que os habitantes de Coimbra nutrem pelo Mondego, o "rio dos poetas", e é complementada com breves explicações sobre oito monumentos da cidade. ${ }^{9}$ A Universidade merece uma rubrica exclusiva, onde se expõe brevemente a sua história. As tradições estudantis são explicadas na relação com a universidade, dando-se relevo único à Queima das Fitas.

Os três guias são bastante separados no tempo (1924, 1996 e 2007) e possuem naturezas distintas, na medida em que a sua elaboração partiu de lógicas, objectivos e públicos variados: ou mais virados para relatos de viagem, ou mais direccionados para consumo turístico imediato. Em consequência, o turista, o visitante ou o simples viajante, terá acesso a quantidades maiores ou menores de informação, expostas de forma mais ou menos detalhada, e conhecerá mais ou menos cidade, dependendo da fonte consultada.

Como sugere I. Barreira (2005), os guias são um lugar peculiar de construção de narrativas e, portanto, dependendo do guia, também a cidade apresentada é diferente: mais completa, com maior densidade de descrição histórica e patrimonial, e com um conjunto de informações acessórias, como o guia da Fundação Calouste Gulbenkian; ou mais curta, mais directa e apenas com os dados essenciais, como o do jornal Expresso ou, mais notoriamente, o da American Express. Ainda assim, há aspectos recorrentes na apresentação da cidade: o seu papel na formação da nacionalidade, a importância da universidade, a vivência estudantil, a densidade histórica, os mitos e lendas, e a sua riqueza patrimonial estão presentes em todos os guias. Estes aspectos traduzem-se em imagens recorrentes da cidade. Nos três guias, Coimbra é uma cidade universitária, uma cidade dos estudantes e uma cidade histórica.

Apesar dos traços comuns, há também algumas discrepâncias: se alguns guias se concentram no centro da cidade para a sua descrição, outros apresentam uma visão de conjunto mais alargada, referindo-se ao outro lado do Rio Mondego, muitas vezes menosprezado nas actividades turísticas da cidade.

\footnotetext{
9 São aqui referenciados a Sé Velha, a Sé Nova, o Museu Nacional Machado de Castro, Santa Cruz, o Jardim Botânico, Santa Clara-a-Velha, Santa Clara-a-Nova e o Portugal dos Pequenitos.
} 
O objectivo geral dos guias passa por uma apresentação da cidade através da recomendação de visita a determinados locais, evitando desvios ao modo planeado de conhecer a cidade. Esta tentativa de mostrar a cidade seleccionada leva ao uso de uma linguagem de exaltação dos lugares; daí que, independentemente do guia, o que merece realce é a utilização constante de superlativos de superioridade para caracterizar a cidade como a mais "qualquer coisa": a mais antiga, bonita, ilustre, notável, admirável, ou qualquer outro adjectivo que a distinga de outras cidades.

\section{O imaginário da cidade nos mercados turísticos}

Que aspectos da cidade são postos em relevo e que dimensões são esquecidas na promoção turística? Que qualidades, ideais ou imaginárias, são publicitadas? Que perfil, ou perfis de cidade emergem no imaginário turístico? Que relação estabelecem esses perfis com as características materiais e socioculturais da cidade contemporânea, da sua história e da sua autorepresentação? Estas são algumas das interrogações que serviram de fio condutor à análise das imagens que circulam na esfera da promoção turística e, de forma mais ampla, dos modos como a cidade é apresentada e representada nos instrumentos de promoção no sector turístico privado.

É nesses instrumentos que se podem efectivamente encontrar as imagens publicitárias que identificam e qualificam a cidade como um destino nos mercados turísticos. Nessas imagens promocionais podemos encontrar, traduzidos, retrabalhados e re-significados os vários tipos de imagens, representações e narrativas que, historicamente, se foram constituindo acerca da cidade. Elas foram, por isso, interpretadas como produtos do trabalho de (re)tradução simbólica que os operadores turísticos desempenham.

Como forma de captar a complexidade deste objecto, privilegiou-se uma abordagem de cariz essencialmente qualitativo, mais passível de produzir informação relevante para o estudo da forma e dos conteúdos das imagens e das narrativas sobre a cidade. A análise baseou-se num conjunto de 150 programas, organizados por operadores de vários países, que incluem a cidade, seja como ponto de passagem num circuito mais amplo (105 casos), seja em guias informativos ( 20 casos) com instruções para conhecer cidades ou atracções turísticas, seja ainda em programas direccionados para a cidade no âmbito de estadias em determinados hotéis $(25$ casos $){ }^{10}$

\footnotetext{
${ }^{10}$ Consideram-se circuitos turísticos os programas que, para além da cidade de Coimbra, contemplam a passagem por outros locais do país ou estrangeiro. Por guias informativos entendem-se as partes das páginas electrónicas dos operadores dedicadas a informações sobre a cidade. Não se tratando dos típicos guias turísticos, como os que atrás foram apresentados, este tipo de guia apresenta, ainda assim, material bastante interessante para análise. Consideram-se estadias na cidade todos os programas, habitualmente de 2 ou 3 dias, que se dirigem apenas à cidade de Coimbra.
} 
O material recolhido foi duplamente analisado: através de uma lógica quantitativa inicial, a partir da qual os programas foram caracterizados em termos gerais, do ponto de vista da sua abrangência geográfica, duração temporal e proporção dedicada a Coimbra; e de uma lógica qualitativa posterior, centrada na análise dos textos que acompanham cada programa. Partiu-se de um trabalho de análise categorial que, embora não siga à risca a Grounded Theory, foi baseado nas técnicas que A. Strauss propõe (cf. 1987; Strauss e Corbin, 1998). Não sendo sempre possível identificar as propriedades e as dimensões das categorias analíticas, tal como Strauss indica, optou-se por seguir as sugestões quanto aos processos de codificação e construção de categorias, recorrendo, por acréscimo, aos processos de classificação temática sugeridos por G. MacCracken (1988). Esta análise permitiu a identificação de um conjunto de imagens da cidade, sistematicamente presentes nos textos dos programas turísticos, bem como de uma série de articulações entre essas imagens: umas mais fortes do que outras, umas mais recorrentes do que outras.

Sobre os efeitos que tais imagens têm nos comportamentos e percepções dos turistas e na auto-representação da comunidade local, este trabalho não permite indagar. ${ }^{11}$ Mas o confronto destas imagens com as dinâmicas que estruturam morfológica, económica, social e culturalmente a cidade contemporânea, com as políticas que sobre ela intervêm e com os discursos que sobre ela reflectem localmente, permite certamente sondar o grau em que a cidade reage material e simbolicamente a esse imaginário que projecta para fora de si mesma. É esse exercício que o texto ensaia também.

Um lugar pode ser associado a mais do que uma imagem, na medida em que, tal como sugerem C. Fortuna e P. Peixoto (2002: 18), ele "pode difundir uma pluralidade de imagens, reais ou imaginárias, instantâneas ou duradouras, de consenso ou de conflito, individuais ou colectivas". É nesta linha de ideias que pretendo demonstrar a existência de várias cidades nos programas turísticos, ou, melhor, a presença de várias imagens publicitárias e de grande heterogeneidade na forma como a cidade é turisticamente promovida, de acordo com os objectivos promocionais e comerciais dos operadores turísticos envolvidos.

$\mathrm{Na}$ sequência da análise, proponho a existência de três perfis de cidade, associados ao tipo de programa turístico: a "cidade dos circuitos turísticos", a "cidade dos guias informativos" e a "cidade das estadias". Esta heteroge-

\footnotetext{
${ }^{11}$ A dissertação de mestrado que constitui a base do presente artigo não se debruça sobre estas dimensões analíticas, complementares a uma abordagem global do fenómeno turístico em Coimbra. Essas outras dimensões vêm sendo estudadas no âmbito do projecto "Fluxos turísticos no centro histórico de Coimbra", referido na nota 1.
} 
neidade implica que os recursos locais promovidos, os elementos realçados, a importância que é dada à cidade e, em última análise, todo o imaginário com ela relacionado, variem em função dos três tipos de programas e das lógicas subjacentes à sua produção e comercialização. Coimbra ora é uma cidade histórica, ora tradicional, ora universitária, ora dos estudantes, ora arquitectónica, ora do fado e ora do Mondego, ${ }^{12}$ imagens da cidade que, recuperadas pelos operadores em função dos objectivos de cada programa, se associam e articulam na constituição dos três perfis.

Em geral, os textos usados para a apresentação de Coimbra nos circuitos turísticos (entre os quais se mostram, de seguida, três exemplos) são curtos mas frequentemente adjectivados, o que lhes confere uma linguagem próxima da poética, seduzindo os turistas e apelando à sua identificação subjectiva e emocional. Nesses textos, Coimbra é traduzida como uma cidade universitária, dos estudantes, tradicional, histórica e arquitectónica.

Your tour brings you to the Old University town of Coimbra where 13,000 University students wear long black robes under black capes with facings of different colours for the various schools. The Praça do Comercio, the town's old market place, is now one of the most impressive squares in Portugal. The Old University is located on the highest point of the upper town where the Royal Palace once stood. Partly rebuilt in the 17th and 18th centuries, an iron gate leads into a fine courtyard enlaced on three sides by buildings from the terrace on the south side. (C.70)

Continuação para a histórica e monumental Coimbra de muitas tradições, principalmente ligadas aos estudantes da antiga e prestigiada Universidade. (C.92) O terceiro dia do nosso itinerário irá levar-nos até à cidade dos estudantes: Coimbra. Com uma das Universidades mais antigas da Europa, Coimbra tem-se destacado como um centro de conhecimento e cultura Portuguesa nos últimos sete séculos. Uma visita à velha Universidade (ainda em funcionamento) irá dar-lhe uma perspectiva detalhada sobre o sistema de ensino em Portugal assim como uma excelente oportunidade para perceber a enorme influência que a população Judaica teve no sistema educativo de Portugal. (C.123)

A imagem de Coimbra como cidade histórica remete para o papel relevante que tem vindo a desempenhar na história e na cultura portuguesas,

\footnotetext{
12 As expressões em itálico enunciam as imagens da cidade construídas a partir da análise categorial do material empírico. Nalguns casos, como sugere A. Strauss (1987: 33; Strauss e Corbin, 1998: 115-116), trata-se de in vivo codes, ou seja, de expressões usadas nos próprios textos pelos operadores, noutros casos são expressões minhas para sintetizar ideias expressas nesses textos.
} 
contribuindo para o seu grau de importância no contexto nacional. Aponta igualmente para uma vasta riqueza monumental, que lhe permite reunir um conjunto de interessantes testemunhos do passado. Para esta riqueza muito contribui outra imagem, a de cidade universitária, que resulta de uma universidade antiga e famosa que coloca Coimbra no centro das rotas do conhecimento e da cultura.

A imagem da cidade universitária é a mais frequentemente usada pelos operadores na promoção turística de Coimbra. Não se trata de uma cidade com uma infraestrutura educativa comum a inúmeras outras cidades, mas sim de uma ilustre cidade universitária. Interessante, também, é a referência ao facto de a universidade estar ainda em funcionamento, apesar de velha. Trata-se, aqui, de invocar uma imagem de património vivo que permite aos turistas apreciar o conjunto edificado da universidade, não como se de um museu se tratasse, mas como um monumento vivo pelo serviço educativo que está ainda em uso, e que aponta, por sua vez, para a cidade dos estudantes. É no ambiente urbano de uma cidade universitária, com uma universidade antiga e, portanto, de uma cidade antiga, que cerca de $13.000^{13}$ estudantes vestem capas e batinas negras. Aqui se encontra um dos pontos de articulação mais fortes, usados pelos operadores turísticos, entre a cidade, a universidade e os estudantes: as tradições académicas.

Sendo responsabilizados por um constante rejuvenescimento da cidade, os estudantes reinventam continuamente as suas tradições, contribuindo, por isso, para a cidade tradicional. Nos circuitos turísticos, esta cidade tradicional surge unicamente relacionada com a esfera universitária, através das tradições, onde se incluem a música e o traje universitário. Nos guias informativos, esta cidade é enriquecida, somando-se aos elementos anteriores outro conjunto de tradições ligadas ao artesanato e, em particular, à cerâmica de Coimbra.

Por fim, a imagem de cidade arquitectónica é transversal a todas as anteriores. Tratando-se de um ambiente urbano que é apresentado como possuindo verdadeiras jóias da arquitectura portuguesa, e de vários tipos de arquitectura, os programas turísticos assumem que a cidade é um núcleo extraordinário de arte.

Tal como nos circuitos turísticos, também nos guias informativos (de que se apresentam a seguir três exemplos) a cidade universitária é a imagem mais recorrente. Também neste segundo conjunto de materiais são visíveis as

\footnotetext{
${ }^{13}$ Há muito que este número foi ultrapassado, mas continua presente nos textos actuais de promoção turística, facto que não deixa de revelar alguma falta de cuidado dos operadores na actualização dos materiais promocionais.
} 
analogias entre a antiguidade da universidade e da cidade, reforçando-se a íntima relação entre as duas. O que nos guias é verdadeiramente novo é o fado e o Mondego.

Aqui nasce o rio Mondego, que vem abraçar a cidade de Coimbra, onde é cantado há tantos séculos pelos estudantes universitários. (G.2)

Aqui, o Fado teve, desde sempre, um estilo mais elevado e romântico, a que não será estranho o facto da cidade possuir, desde 1290, uma comunidade estudantil. É natural que uma herança, invisível mas significativa do ponto de vista histórico e cultural, tenha contribuído para dar ao Fado um carácter erudito e uma auréola mais romântica. Coimbra, ao contrário de Lisboa, não possui porto e terá sido a sua posição geográfica que, em conjunto com uma forte tradição cultural de origem monástica e universitária, terá decididamente contribuído para a forma específica do Fado de Coimbra. (G.39)

Sede da mais antiga universidade de Portugal, Coimbra é uma cidade sobretudo animada pelos estudantes que vivem e estudam aqui, mas está também cheia de monumentos e tesouros históricos e conta com um comércio movimentado e a presença vibrante do Mondego, o "Rio dos Poetas" como os habitantes locais the chamam orgulhosamente, oferecendo ao visitante a beleza das suas margens e alimentando os campos férteis do vale circundante. Coimbra oferece muitos outros sítios a explorar e um vasto calendário de eventos culturais e de diversão, mas torna-se especialmente apetecível em Maio, quando os estudantes celebram o final do ano académico com a tradicional Queima das Fitas, enchendo as ruas de música e animação esfuziante. (G.142)

A cidade do fado está intimamente relacionada com a dos estudantes e a universitária. Atribui-se à universidade e respectiva comunidade estudantil a especificidade do fado de Coimbra e estabelece-se a diferença com outros tipos de fado, nomeadamente o de Lisboa, que foi influenciado por um porto marítimo. Coimbra não tem porto, mas tem rio, e é a este rio que se deve a última das imagens da cidade dos guias informativos: a cidade do Mondego. Nestes textos, recorre-se a todo um imaginário em torno da universidade e das tradições académicas, relacionando-se-lhes o rio e remetendo para um universo mítico sobre a vivência dos estudantes na cidade.

O rio Mondego é encarado de diversas formas por estes guias: ora pela beleza que as suas margens oferecem, ora pelo alimento das terras que o envolvem, ora por ser cantado pelos estudantes e servir de inspiração aos poetas da cidade. Mas, também, simplesmente devido ao aspecto da cidade que se ergueu no cimo de uma colina sobre ele. Para além da alusão ao rio e ao passeio agradável que as suas águas proporcionam, refere-se a variedade 
da gastronomia existente na cidade, devida em particular à localização da cidade entre o rio e a montanha. Este é, portanto, um aspecto novo valorizado nos guias: a gastronomia. A promoção da cidade e a re-significação do rio dá-se, aqui, menos pela sua dimensão histórico-cultural e mais pelo lado da cultura etnográfica local.

A cidade que emerge dos guias é muito mais plural do que a dos circuitos que, apesar das cinco imagens que convoca, está sempre mais centrada na história, no património e na Universidade. O imaginário da cidade que surge dos guias, embora conceda uma grande importância a estes três elementos, é bastante mais diverso, abrindo-se para dar um lugar maior aos modos de cultura urbana que se vivem na cidade.

Por fim, a cidade das estadias é uma cidade mais árida do ponto de vista da sua caracterização. Ainda que reúna algumas das imagens anteriormente identificadas, é uma cidade fugaz e resumida, sem história e com poucas tradições. É uma cidade mais de hotéis e menos das características que lhe são atribuídas pelos circuitos turísticos ou guias informativos. É uma cidade fragmentada ou esvaziada de conteúdos, onde os lugares importam menos do que os programas de lazer.

É, portanto, uma cidade breve e quase sem qualidades singulares, onde os turistas se limitam a visitar um conjunto muito específico de locais, incluídos a priori num pacote turístico. Nestes programas, os turistas passam a maior parte do seu tempo no hotel, deixando-o apenas para conhecer os ex-libris da cidade - o fado e o rio Mondego - embora sem qualquer necessidade de compreender a história ou as tradições para as quais estes elementos remetem. Mais do que cidade breve, ela é, talvez, um território e uma localização acidental, na medida em que os serviços hoteleiros são mais importantes do que a cidade. Esta vê-se esvaziada do seu conteúdo histórico, cultural, social e simbólico. Isto significa que, se o turismo tem a capacidade de promover a regeneração económica das cidades e a valorização das suas características históricas, culturais e simbólicas, ele tem também o poder de desqualificar, des-significar e des-diferenciar a cidade, transformando-a apenas na localização acidental de uma experiência que, por estar centrada noutras dimensões, é evasiva ou fugaz em relação à cidade.

\section{Entre a cidade real e a cidade turística}

Neste texto pretendeu-se reflectir sobre a produção do imaginário turístico de Coimbra, atentando nas imagens e narrativas seleccionadas, (re)criadas e usadas para apresentar a cidade ao exterior, nos mercados turísticos nacionais e internacionais. Deste ponto de vista, a investigação partiu do pressuposto de que a dimensão turística desta cidade constituía um objecto empí- 
rico especialmente rico, não só em si mesmo, mas como um laboratório onde as tendências mais gerais sobre o turismo urbano e cultural e sobre a produção imagética dos lugares para fins turísticos poderiam ser analisadas e compreendidas.

Num momento em que as actividades turísticas são politicamente encaradas como uma possibilidade de revitalização e desenvolvimento social e económico dos territórios urbanos, elas assumem uma importância estratégica acrescida em cidades como Coimbra, cujos centros antigos vêm sofrendo alguma desvitalização, fruto do afastamento de algumas das suas funções principais. Embora as actividades mais directamente relacionadas com o sector turístico não se mostrem preponderantes na economia da cidade, o turismo não deixa, ainda assim, de representar uma estratégia importante nas políticas públicas, tal como revelam os projectos recentes de intervenção urbana e os discursos dos responsáveis políticos e dos intervenientes na esfera turística da cidade. É neste sentido que os processos de recriação de imagens e narrativas urbanas, associados ao desenvolvimento do sector turístico, se mostram relevantes, não só para o modo como a experiência turística é vivida, mas também para as formas como a cidade redefine a sua identidade, vê definidas as suas agendas políticas de planeamento urbano e, constituindo-se como um lugar turístico, se reorganiza material, simbólica e imageticamente.

As imagens e as narrativas turísticas são construídas por um conjunto de actores, a partir de repertórios determinados e mediante processos específicos. Das articulações entre estes diversos tipos de actores, com as suas lógicas de actuação e com os seus interesses, resultam, forçosamente, imagens e visões polissémicas e fluidas da cidade. A polissemia é observável nos materiais de promoção analisados, a partir dos quais a cidade de Coimbra vai sendo representada nas suas dimensões histórica, universitária, estudantil, tradicional, arquitectónica, do fado e do Mondego. São estas as sete imagens que, em conjunto, formam um imaginário turístico mais vasto, comercializado pelos operadores nos mercados turísticos.

Nesta análise, tornou-se clara a posição fundamental que a Alta e a Baixa - as zonas que delimitam o centro histórico da cidade - detêm no imaginário turístico. As duas zonas surgem muito diversamente representadas nesse imaginário: é a Alta que se destaca, nas suas dimensões histórica, monumental e patrimonial, contrastando com a Baixa que é razoavelmente invisibilizada. A compreensão desta dualidade do espaço urbano implica, porém, que se considerem em conjunto a Alta e a Baixa, porque, tanto historicamente como hoje, os dois espaços se constituem, morfológica, funcional e simbolicamente, em relação um com o outro. Isto permite com- 
preender que, embora revestindo-a de novos sentidos, as imagens turísticas da cidade, mais centradas na Alta, reproduzem a hierarquia social e simbólica que, no passado como hoje, define a relação entre esses dois espaços. O imaginário turístico da cidade reforça, assim, a dualidade e a hierarquia que distingue a Alta e a nobilita face à Baixa, o que certamente tem também efeitos sobre o modo como os dois espaços são percebidos e simbolicamente valorizados pela comunidade local, ou abordados pelos planeadores e decisores políticos.

Como qualquer cidade, Coimbra tem os seus altares e os seus interditos (Lopes, 2001). Se a história, a universidade, os estudantes, as tradições, o valor arquitectónico, o fado e o Rio Mondego constituem os recursos apresentados no mercado turístico, eles são, por assim dizer, os altares da cidade, contrastando com os elementos ou recursos ausentes da cidade turística imaginada, relegados para a posição de interditos ou esquecimentos.

Um primeiro elemento esquecido diz respeito à oferta cultural da cidade, ausente quase por completo do imaginário turístico urbano. Embora algumas instituições responsáveis pela promoção turística da cidade organizem agendas culturais e de eventos, estes não constituem, de forma geral, elementos suficientemente atractivos para a captação de turistas. Muito raramente se encontra, na promoção que é feita pelos agentes do sector privado, referência a encontros ou espectáculos de música, exposições artísticas, peças de teatro, feiras de livro, artesanato ou música.

Um segundo elemento remete para os modos de vida da população não estudantil. Segundo diversas perspectivas teóricas (cf. Costa, 2003 e 1999; Michel, Bassand e Lehmann, 1982; Rémy e Voyé, 1994), os centros antigos das cidades são espaços propícios à formação de uma identidade cultural, ao desenvolvimento de sentimentos de pertença em relação ao espaço urbano e à presença de manifestações populares fortes, pese embora a diversidade dos estilos de sociabilidade que diferentes espaços urbanos comportam. Todas estas dimensões são parte integrante dos modos de vida das populações e da identidade sócio-espacial no centro antigo da cidade. No entanto, nenhuma delas é destacada pelas imagens da cidade turisticamente promovida. No que respeita aos modos de vida e aos hábitos culturais da população, nenhuma referência se faz, por exemplo, às lavadeiras do Mondego, às tricanas, ou à população rural que ainda hoje vem à cidade vender os seus produtos, povoando feiras e festas populares. Apenas as tradições, os rituais e a boémia são salientadas, como características inerentes à comunidade estudantil da cidade.

Em terceiro lugar, não um mas vários elementos esquecidos merecem aqui realce. Refiro-me, por um lado, aos espaços verdes da cidade, de onde 
podem destacar-se o Choupal, Vale de Canas, o Jardim da Sereia e o Jardim Botânico, recursos aproveitados de forma deficitária para a construção das imagens turísticas da cidade. Adicionalmente, vários monumentos não são referidos nesse imaginário, nomeadamente o Convento de S. Francisco, a Lapa dos Esteios e toda uma série de igrejas e conventos localizados numa das principais artérias da cidade, a Rua da Sofia. Estes lugares são, no entanto, referências importantes noutros imaginários que, também eles, compõem no plano simbólico a identidade da cidade. Por fim, sendo seleccionadas algumas partes específicas da história onde a cidade é engrandecida, a sua componente muçulmana, que durou mais de três séculos, acaba por ser remetida para um lugar secundário.

Estes esquecimentos, por oposição aos lugares de destaque, concentram a cidade turística numa área bem específica e delimitada da cidade real: ela não é sequer o centro histórico na sua totalidade, baseia-se antes, e maioritariamente, na Alta universitária, para onde a cidade remete as suas origens.

Um último interdito, decorrente em parte do anterior - da concentração geográfica da cidade turística - diz respeito à desvalorização razoável das novas zonas da cidade, em torno do centro histórico. Mais modernas e dotadas de equipamentos desportivos e de grandes superfícies comerciais, estas zonas parecem não constituir elementos suficientemente atractivos para serem mostrados e incluídos nas experiências turísticas organizadas.

Apuradas estas ausências no imaginário turístico, a relação entre a cidade, a cultura e o património em Coimbra deverá ser re-equacionada, na medida em que a cultura, como arte e erudição, está razoavelmente ausente. Neste ambiente turístico urbano, a relação entre os três elementos constitui o segmento turístico mais sedutor apenas se se entender a cultura no seu sentido mais flexibilizado e amplo, associando ao universo cultural as expressões culturais dos modos de vida das populações, ainda que em Coimbra estas estejam circunscritas à população estudantil.

\section{Conclusão}

O imaginário constituído pelas sete imagens que descrevi envolve aproximações e distâncias à cidade real: com os seus lugares de destaque e os seus lugares esquecidos, ele narra uma entre várias cidades possíveis, através da selecção e valorização de alguns recursos do local em detrimento de outros. Esse imaginário comporta, por sua vez, proximidades e distâncias também à cidade que é projectada pelo poder político e que, porventura, confere já uma atenção maior a zonas para além da cidade turística encontrada.

Este universo simbólico é, naturalmente, complexo e heterogéneo. A investigação procurou captar uma parte desse universo, olhando as imagens e 
as narrativas que circulam na promoção turística, privilegiando canais específicos de divulgação. As imagens que captei da Coimbra turística coexistem com outras, sejam as que emergem de outros contextos semânticos que a esfera turística gera, sejam as que decorrem dos vários outros registos por onde corre o trabalho de representação simbólica da cidade. Nas reconstruções que a investigação desvendou, encontra-se uma cidade que ora é histórica, ora universitária, dos estudantes, tradicional, arquitectónica, do fado, ora do Mondego. Nessas suas declinações, a cidade do imaginário turístico não existe isolada, dialogando com outros imaginários urbanos, mais próximos ou distantes da cidade vivida, da sua história, do seu quotidiano.

Se esta investigação capta uma parte do universo simbólico em que se (re)produzem os imaginários e as representações da cidade de Coimbra - a parte ditada pelas opções teóricas e analíticas que foram sendo tomadas ao longo do trabalho - outras investigações captariam, certamente, imagens e narrativas diferentes e dimensões distintas da cidade turística. Quanto a essas outras partes, elas estão ainda por desvendar, garantindo que a riqueza do objecto de pesquisa se mantém, e que este, para além da sua atractividade turística, continua a sustentar a sua atractividade sociológica.

\section{Referências bibliográficas}

Baptista, Luís Vicente (2003), “Territórios, imagens e poderes”, in Graça Índias Cordeiro; Luís Vicente Baptista; António Firmino da Costa (orgs.), Etnografias urbanas. Oeiras: Celta Editora, 35-42.

Barreira, Irlys (2005), “Os guias turísticos em Berlim”, Tempo Social, Revista de Sociologia da USP, 17(1), 299-320.

Barthes, Roland (1957), “O Guia Azul”, in R. Barthes, Mitologias. Lisboa: Edições 70.

Boyer, M. Christine (1998), The City of Collective Memory. Its Historical Imagery and Architectural Entertainments. Cambridge, Mass: MIT Press.

Bridge, Gary; Watson, Sophie (2003), “City Imaginaries”, in Gary Bridge; Sophie Watson (orgs.), A Companion to the City. Malden: Blackwell Publishing, 7-17.

Chartier, Roger (1988), A bistória cultural. Entre práticas e representações. Lisboa: DIFEL.

Costa, António Firmino da (1999), Sociedade de bairro. Oeiras: Celta Editora.

Costa, António Firmino da (2003), "Estilos de Sociabilidade”, in Graça Índias Cordeiro; Luís Vicente Baptista; António Firmino da Costa (orgs.), Etnografias urbanas. Oeiras: Celta Editora, 121-129.

Dicionário Houaiss da Língua Portuguesa (2003), "Narrativa”. Lisboa: Temas e Debates. 
Dionísio, Sant'Anna (1988), Guia de Portugal - Beira Litoral, Vol. 3. Lisboa: Fundação Calouste Gulbenkian [1924].

Donald, James (2003), “The Immaterial City: Representation, Imagination, and Media Technologies”, in Gary Bridge; Sophie Watson (orgs.), A Companion to the City. Malden: Blackwell Publishing, 46-54.

Finnegan, Ruth (1998), Tales of the City. A Study on Narrative and Urban Life. Cambridge: Cambridge University Press.

Fortuna, Carlos (1999), Identidades, percursos, paisagens culturais: Estudos sociológicos de cultura urbana. Oeiras: Celta Editora.

Fortuna, Carlos (2006), "Centros históricos e patrimónios culturais urbanos. Uma avaliação e duas propostas para Coimbra”, Oficina do CES, 254.

Fortuna, Carlos; Ferreira, Claudino (1996), "O turismo, o turista e a (pós)modernidade", Oficina do CES, 80.

Fortuna, Carlos; Peixoto, Paulo (2002), “A recriação e reprodução de representações no processo de transformação das paisagens urbanas de algumas cidades portuguesas", in Carlos Fortuna; Augusto Santos Silva (orgs.), Projecto e circunstância: Culturas urbanas em Portugal. Porto: Edições Afrontamento, 17-63.

Geertz, Clifford (1973), The Interpretation of Culture. New York: Basic Books.

Gomes, Margarida Maria Reis (1995), A reconversão de antigos espaços industriais Estudo da área central de Coimbra. Coimbra: Faculdade de Letras da Universidade de Coimbra, Dissertação de Mestrado em Geografia.

Gomes, Carina Sousa (2005), Modos de vida nas cidades e processos de reabilitação urbana: O caso da Baixa de Coimbra. Dissertação de Licenciatura em Sociologia. Coimbra: Faculdade de Economia da Universidade de Coimbra.

Gomes, Carina Sousa (2007), "Viver no centro da cidade: Práticas, discursos e representações sobre a Baixa de Coimbra", Oficina do CES, 280.

Gomes, Carina Sousa (2008), A (re)criação dos lugares. Coimbra: cidade e imaginário turístico. Dissertação de Mestrado em Sociologia. Lisboa: Faculdade de Ciências Sociais e Humanas da Universidade Nova de Lisboa.

Gómez, Manuel (1998), "Patrimonio e ciudad: nuevos escenarios de promoción y gestión del turismo urbano europeo privado", Sociedade e Território, Revista de estudos urbanos e regionais, 28, 10-22.

Kotler, Philip et al. (1993), Marketing Places - Attracting Investment, Industry, and Tourism to Cities, States, and Nations. New York: The Free Press.

Kotler, Philip; Haider, Donald (1994), “There's No Place Like Our Place!”, Public Management, 76(2), 15-18.

Lopes, João Teixeira (2001), "Identidades, estilos, repertórios culturais. Um certo ponto de vista sobre a cidade”, in Magda Pinheiro; Luís Vicente Baptista; Maria João Vaz (orgs.), Cidade e metrópole. Centralidades e marginalidades. Oeiras: Celta Editora, 181-194. 
Lourenço, Luciano; Matos, Mário (1996), "Retrato Demográfico”, Guia Expresso das Cidades e Vilas Históricas de Portugal, Vol. 7, 8-9.

Lynch, Kevin (1988), A imagem da cidade. Lisboa: Edições 70 [1960].

MacCannell, Dean (1999), The Tourist: A New Theory of the Leisure Class. London: Macmillan.

MacCracken, Grant (1988), The Long Interview. London: Sage Publications.

McDonald, Ferdie (org.) (2007), Guia American Express: Portugal. London: Dorling Kindersley Limited.

Michel, Barbara; Bassand, Michel; Lehmann, Philippe (1982), "Le voisinage: Un théâtre expérimental de la vie quotidienne", Espaces et sociétés, 41, 51-69.

Orbasli, Aylin (2000), Tourists in Historic Towns: Urban Conservation and Heritage Management. London: E \& FN Spon.

Rémy, Jean; Voyé, Liliane (1994), A cidade: Rumo a uma nova definição?. Porto: Edições Afrontamento.

Rosmaninho, Nuno (2006), “Coimbra no Estado Novo”, in C.M.C., Exposição: Evolução do espaço físico de Coimbra. Coimbra: C.M.C., 65-92.

Rossa, Walter (2006), "O espaço de Coimbra: Da instalação da urbanidade ao fim do antigo regime”, in C.M.C., Exposição: Evolução do espaço físico de Coimbra. Coimbra: C.M.C., 17-42.

Rossa, Walter (1996), “A musa do Mondego”, Guia Expresso das Cidades e Vilas Históricas de Portugal, Vol. 7, 5-7.

Saraiva, José Hermano (1996), “A história de Coimbra”, Guia Expresso das Cidades e Vilas Históricas de Portugal, Vol. 7, 3-4.

Shields, Rob (1992), Places on the Margin - Alternative Geographies of Modernity. London / New York: Routledge.

Strauss, Anselm (1987), Qualitative Analysis for Social Scientists. Cambridge: University Press.

Strauss, Anselm; Corbin, Juliet (1998), Basics of Qualitative Research. Techniques and Procedures for Developing Grounded Theory. London: Sage Publications.

Urry, John (1990), The Tourist Gaze: Leisure and Travel in Contemporary Societies. London: Sage Publications. 